\title{
Suspended plate antenna with circular polarization and configurable sense of rotation
}

\section{Antena de placa suspendida con polarización circular y sentido de giro configurable}

DOI: http://doi.org/10.17981/ingecuc.16.1.2020.011

Artículo de Investigación Científica. Fecha de Recepción: 25/09/2018. Fecha de Aceptación: 24/09/2019

\author{
Carlos Arturo Suarez Fajardo \\ Universidad Distrital Francisco José de Caldas. Bogotá, D.C. (Colombia) \\ csuarezf@udistrital.edu.co \\ Jeison Jair Ariza Pulido (1) \\ Universidad Distrital Francisco José de Caldas. Bogotá, D.C. (Colombia) \\ jjarizap@correo.udistrital.edu.co \\ Sergio Esteban Mejía Serrano (i) \\ Universidad Distrital Francisco José de Caldas. Bogotá, D.C. (Colombia) \\ semejias@correo.udistrital.edu.co \\ Gustavo Adolfo Puerto Leguizamón \\ Universidad Distrital Francisco José de Caldas. Bogotá, D.C. (Colombia) \\ gapuerto@udistrital.edu.co
}

Para citar este artículo:

C. Suarez Fajardo. J. Ariza Pulido, S. Mejía Serrano y G. Puerto Leguizamón, "Suspended plate antenna with circular polarization and configurable sense of rotation”, INGE CUC, vol. 16, no. 1, pp. 156-170, 2020. DOI: http://doi.org/10.17981/ingecuc.16.1.2020.011

\section{Resumen}

Introducción- Las Antenas con Polarización Circular (APC) permiten reducir el efecto de rotación de Faraday debido a la presencia de la ionosfera, el cual ocasiona una significante pérdida de potencia frente al caso de utilizar antenas con polarización lineal (ALP). Por lo tanto, estas antenas son ampliamente utilizadas para aplicaciones en telemetría espacial de satélites, sondas espaciales y misiles balísticos entre otras. Por otra parte, las Antenas de Placa Suspendida (APS) brindan la posibilidad de obtener mayores niveles de ganancia máxima y ancho de banda de impedancia frente a las tecnologías convencionales. Así mismo, resulta útil el poder seleccionar el sentido de giro más apropiado, dependiendo de las condiciones de propagación en los enlaces de subida/bajada.

Objetivo- Diseñar una APC con sentido de giro seleccionable para aplicaciones en satélites pequeños, usando la tecnología APS, tal que posea niveles de ganancia y ancho de banda superiores a las obtenidas con tecnologías convencionales.

Metodología- El diseño de la antena parte de modelos propuestos en la literatura, mediante los cuales se diseña una geometría inicial compuesta por un parche suspendido con alimentación en L y un acoplador híbrido, para luego optimizar dicha geometría mediante análisis paramétricos llevados a cabo con simuladores electromagnéticos apropiados.

Resultados- El diseño propuesto presenta un ancho de banda de impedancia del $34.39 \%$ y una ganancia máxima de $8.75 \mathrm{dBi}$ a una frecuencia de $2.35 \mathrm{GHz}$.

Conclusiones- La técnica de alimentador en forma de L para parches suspendidos mejora el comportamiento de la antena en impedancia, relación axial y ganancia máxima.

Palabras clave- Técnica de alimentación con sonda en forma de L; Polarización circular; Sentido de rotación configurable; Antena de parche suspendida

\begin{abstract}
Introduction- Circular Polarization Antennas (CPA) are able to reduce the "Faraday rotation" effect due to the ionosphere, which causes a significant power losses compared to the case of using linear polarization antennas (LPA). Therefore, these antennas are widely used for space telemetry applications of satellites, space probes and ballistic missiles among others. Furthermore, Suspended Plate Antennas (SPA) offer the possibility to obtain largest levels of maximum gain and impedance bandwidth compared to those obtained with conventional technologies. Likewise, it is useful to be able to select the most appropriate sense of rotation, depending on the propagation conditions in the up/down links.
\end{abstract}

Objective- To design a CPA with configurable sense of rotation for small satellite applications, using SPA technology, such that it has gain and bandwidth levels higher than those obtained with conventional technologies.

Methodology- The antenna design is based on models proposed in the literature, through which an initial geometry consisting of a suspended patch with an L-shaped feeder and a hybrid coupler is designed. Subsequently, geometry optimization by parametric analysis is carried out with appropriate electromagnetic simulators.

Results- The proposed design has an impedance bandwidth of $34.39 \%$ and a maximum gain of $8.75 \mathrm{dBi}$ at a frequency of $2.35 \mathrm{GHz}$.

Conclusions- The L-shaped feeder technique for suspended patches improves the behavior of the antenna in axial ratio, impedance and maximal gain.

Keywords- L shape probe feeding technique; Circular polarization; configurable sense of rotation; Suspended patch antenna 


\section{INTRODUCCTION}

It is well-known that Circular Polarization Antennas (CPA), has many advantages compared to Linear Polarizations Antennas (LPA), namely: CPA are able to reduce the 'Faraday rotation' effect due to the ionosphere, which causes a significant power loss if LPA are employed [1]-[2]. CPA are immune to this problem, thus they are widely used for space telemetry applications of satellites, space probes and ballistic missiles to transmit or receive signal.

In the same way, CPA are very effective in combating multi-path interferences or fading; furthermore, no strict orientation between transmitting and receiving antennas is required [2]. Likewise, it is useful to be able to select the most appropriate sense of rotation, depending on the propagation conditions in the up/down links. These advantages make CPA very attractive for many wireless systems such as mobile and satellite communications systems, radar systems, Global Positioning Systems (GPS, Galileo, etc.) [1]-[2], Global Navigation Satellite Systems (GNSS), wireless sensors, Radio Frequency Identification (RFID) [3], wireless power transmission, Wireless Local Area Networks (WLAN), Wireless Personal Area Networks (WPAN), Worldwide Interoperability for Microwave Access (WiMAX) and Direct Broadcasting Service (DBS) television reception systems [2].

Nowadays, microstrip technology provide an important role in the aforementioned applications due to their low profile, low weight, low cost, ease of manufacture and high integration in circuits and microwave systems [1]-[2]. Nevertheless, the impedance bandwidth and maximum gain limitation of this type of technology has motivated investigations toward its improvement by means of several techniques such as: electromagnetic coupling, slot coupling, stacked patches, use of substrates with large thicknesses and dielectric constants close to the unit, changes in patch geometry, multiple resonance flat configurations, multiple layer configurations, impedance matching networks, periodic logarithmic configurations, ferrite based substrates [2], [4] and Suspended Plate Antennas (SPA), including feeders with L-shaped probes [5].

Furthermore, Circular Polarization (CP) in patch antennas can be achieved using a multifeed technique or a single-feed technique, by means of probe feeds, slot coupled feeds, electromagnetically-coupled feed and Coplanar Waveguide (CPW) feeds [2], at that regard, a Shorted Annular Ring (SAR) antenna design with circular polarization and reconfigurable sense of rotation by means of a $90^{\circ}$ hybrid coupler is presented [6]. The proposed design shows an impedance bandwidth of $33.33 \%$ from $1.9 \mathrm{GHz}$ to $2.66 \mathrm{GHz}$ frequency band, for a reflection coefficient lower than $-10 \mathrm{~dB}$ and maximum gain of $6.1 \mathrm{dBi}$ at a central frequency of $2.35 \mathrm{GHz}$. In the same way, a Shorted Annular Ring (SAR) antenna with Left Hand Circular Polarization (LHCP), improving the axial ratio by means of slits and stubs is presented [7]. The proposed design shows an impedance bandwidth of $3.32 \%$ from $2.37 \mathrm{GHz}$ to $2.45 \mathrm{GHz}$ frequency band, with reflection coefficient lower than $-10 \mathrm{~dB}$ and maximum gain of $6.2 \mathrm{dBi}$ at a central frequency of $2.41 \mathrm{GHz}$.

On the other hand, the design of a right Hand Circularly Polarized Antenna (RHCP) with double resonance is proposed [8]. The design is allowable for simultaneous operation in the GPS bands of $1.227 \mathrm{GHz}$ (L2 band) with a bandwidth of $18.03 \mathrm{MHz}$ and in the L1 band with center frequency of $1.575 \mathrm{GHz}$ and bandwidth of $17.66 \mathrm{MHz}$, for . The gain obtained was $5.4 \mathrm{dBi}$ and $6.8 \mathrm{dBi}$ and axial ratio of $8.1 \mathrm{MHz}$ and $10.2 \mathrm{MHz}$ in the $\mathrm{L} 2$ and $\mathrm{L} 1$ bands respectively. The design consists of two rectangular patches separated by an air space that includes two triangular cuts and two parasitic patches located on opposite sides.

A single-layer dual-broadband circularly polarized antenna that operates at 2.4, 5.2 and 5.8 $\mathrm{GHz}$ for WLAN applications was presented [9]. An annular-slot antenna loaded with a lightning-shaped slot to achieve good CP radiation in the WLAN 2.4 GHz band was studied. To cover the 5.2 GHz WLAN band as well, the inner circular patch of the aforementioned design is modified as an inner ring patch loaded with a notch and a narrow U-shaped strip. The final design can exhibit two wide $3 \mathrm{~dB}$ axial ratio bands of $13.3 \%(2.24-2.56 \mathrm{GHz})$ and $16.9 \%$ (5.01-5.94 GHz), and their corresponding $10 \mathrm{~dB}$ impedance bandwidths are $25.9 \%(2.21-2.86$ $\mathrm{GHz})$ and $25.9 \%(5.05-6.54 \mathrm{GHz})$. 
Also, a printed antenna with wide bandwidth, high gain, and reconfigurable circular polarizations is presented [10]. A loop antenna is printed on both sides of a dielectric substrate: a dual PIN diode loaded loop is printed on one side, while a dual-gap loaded smaller loop is printed on the other side. By controlling the ON-OFF states of the PIN diodes, the polarization of the proposed antenna can be switched electronically to Right-Hand Circular Polarization (RHCP) or Left-Hand Circular Polarization (LHCP). The measured results indicate that the antenna achieves an impedance bandwidth of over $30 \%$, and a $3-\mathrm{dB}$ axial ratio bandwidth of $12.7 \%$ and $14.9 \%$ for RHCP and LHCP, respectively. The measured gain is around $8 \mathrm{dBic}$ for the LHCP state and $7 \mathrm{dBic}$ for the RHCP state.

The feeding technique by means of L-shaped probes was initially proposed [5] to feed a loop antenna. Its principle was later used to excite a microstrip patch using a large substrate with thickness of $6.6 \mathrm{~mm}$ and a dielectric constant close to 1 [11]. This feeding technique offers an interesting solution to the problem of designing antennas on substrates with large thicknesses, considering that due to the integration of the radiating patch along with the L-shaped probe, a capacitive effect is added (parallel section of the feeder with the patch), which at the same time reduces the inductive effect introduced by the vertical section of the L-shaped probe [11]. The approach achieves an impedance bandwidth of $35 \%$ for VSWR $\leq 2$ and an average gain of 7.5 $\mathrm{dBi}$. In the same way, a parametric study for antennas with rectangular geometry, single-port L-shape probe and linear polarization is presented [12]. It is found that the antenna attains $36 \%$ impedance bandwidth (VSWR $\leq 2$ ) as well as $7.0 \mathrm{dBi}$ average gain.

The design of a circular patch fed by three L-shaped probes is presented [13], the patch is supported with four metal poles that short-circuit the patch with the ground plane, thus, two modes of radiating patterns operating on the same frequency are generated, namely: conical and transverse patterns, which make use of two independent "L" shape probes. The resulting bandwidth is $24 \%$ (VSWR $\leq 2)$ and port isolation of $28 \mathrm{~dB}$, the gains are $4 \mathrm{dBi}$ and $8 \mathrm{dBi}$ for conical and transverse modes respectively. Also, the design of an antenna with reconfigurable sense of rotation controlled by a PIN diode and a SPDT switch is proposed [14]. The antenna achieves and impedance bandwidth of $26 \%$ for the two types of polarization (LHCP and RHCP); a gain of $6-7 \mathrm{dBi}$ and an axial ratio bandwidth of $18.4 \%$ for LHCP and $25 \%$ for RHCP.

In the same way, the design of an $8 \mathrm{X} 8$ high gain planar array antenna for $\mathrm{W}$ band $(75 \mathrm{GHz}$ $110 \mathrm{GHz}$ ) operation is presented [15]. The array printed on co-fired ceramic (LTCC) substrate was fed by L shaped probe along with the appropriate feeding network, achieving an impedance bandwidth of $14.9 \%$ from $87 \mathrm{GHz}$ to $101 \mathrm{GHz}$, for $\mathrm{S}_{11} \leq 10$ and a gain of $23.8 \mathrm{dBi}$.

Was proposed that by loading dielectric layers of high relative permittivity into an L-probe fed patch antenna [16], the size of the radiating patch can be minimized to $0.24 \lambda_{0} \times 0.24 \lambda_{0}$ with a thickness of $0.09 \lambda_{0}$ while maintaining the wideband characteristic. The cross polarization level is suppressed; also an identical and symmetric radiation patterns in the E- and H- planes are obtained. In addition, the front-to-back ratio of the antenna can be higher than $20 \mathrm{~dB}$ even with a small ground plane of size $0.725 \lambda_{0}$. The approach achieves an impedance bandwidth of $20 \%$ for $\mathrm{VSWR} \leq 2.0$.

In addition, a stacked patch microstrip antenna combined with a stacked ring microstrip antenna is proposed for quadruple band operation [17]. The two antennas are excited by an L-shaped probe. The impedance bandwidth is enhanced by using double resonance at all frequency bands. The antenna is designed for Wi-Fi (2.45/5.25/5.6GHz bands) and mobile WiMAX (3.5GHz band). Similarly, a triple-band stacked-patch circular-polarized antenna covering $1.166 \mathrm{GHz}-1.289 \mathrm{GHz}, 1.554 \mathrm{GHz}-1.612 \mathrm{GHz}$, and $2.482 \mathrm{GHz}-2.502 \mathrm{GHz}$ is proposed by adopting two shorted annular rings and a four L-probe-feed configuration [18]. The antenna has not only high peak RHCP gain above $5 \mathrm{dBi}$, but also better gain patterns. Furthermore, very symmetrical gain patterns are obtained. The antenna is suitable for high-performance GNSS applications.

Finally, a mechanically reconfigurable patch antenna with polarization diversity is presented [19]. The antenna is composed of a fixed L-probe feed on a bottom substrate layer and a patch with truncated corners on an upper substrate layer that can rotate in azimuth. The Handedness of the Circular Polarization (RHCP or LHCP) may be changed by simply rotating the upper substrate by $90^{\circ}$ with respect to the fixed capacitive coupled feed. The L-probe presented is impedance-matched to patch sizes resonating in the range of $1.0 \mathrm{GHz}-1.8 \mathrm{GHz}$. 
This paper presents the design of a circularly polarized antenna with interchangeable sense of rotation from RHCP to LHCP and vice versa, which consists of a circular suspended patch antenna fed by L-shaped probes through a $90^{\circ}$ hybrid coupler. The proposed design shows an impedance bandwidth of $34.39 \%$ for $\left(\mathrm{S}_{11} \leq-10 \mathrm{~dB}\right)$ and a maximum gain of $8.75 \mathrm{dBi}$ at a frequency of $2.35 \mathrm{GHz}$.

\section{Methodology}

The radiating element of a conventional SPA is a planar plate installed parallel to the ground plane. For the single-element SPA, factors affecting the impedance bandwidth usually include the radiator shape, the feed structure and thickness. Therefore, as compared with the conventional microstrip patch antenna, the design of the SPA actually has one more degree of freedom arising from the spacing between the radiating plate and the ground plane.

Fig. 1 shows the proposed geometry for the circularly configurable sense of rotation antenna (LHCP/RHCP), which is composed by a suspended circular patch, two L-shape probe feeders, and a $90^{\circ}$ hybrid coupler printed on a substrate with square geometry and side of , which in turn defines the total size of the antenna. The radiating patch design is based on the equations for a circular microstrip antenna [1]-[2]. Thus, an initial geometry is defined based on this mathematical model, subsequently, an initial geometry for two L-shape probe feeders are determined based on the proposal presented [12]. Afterwards, an optimization process using parametric analysis on several parameters of the antenna geometry was carried out as explained in the following section.

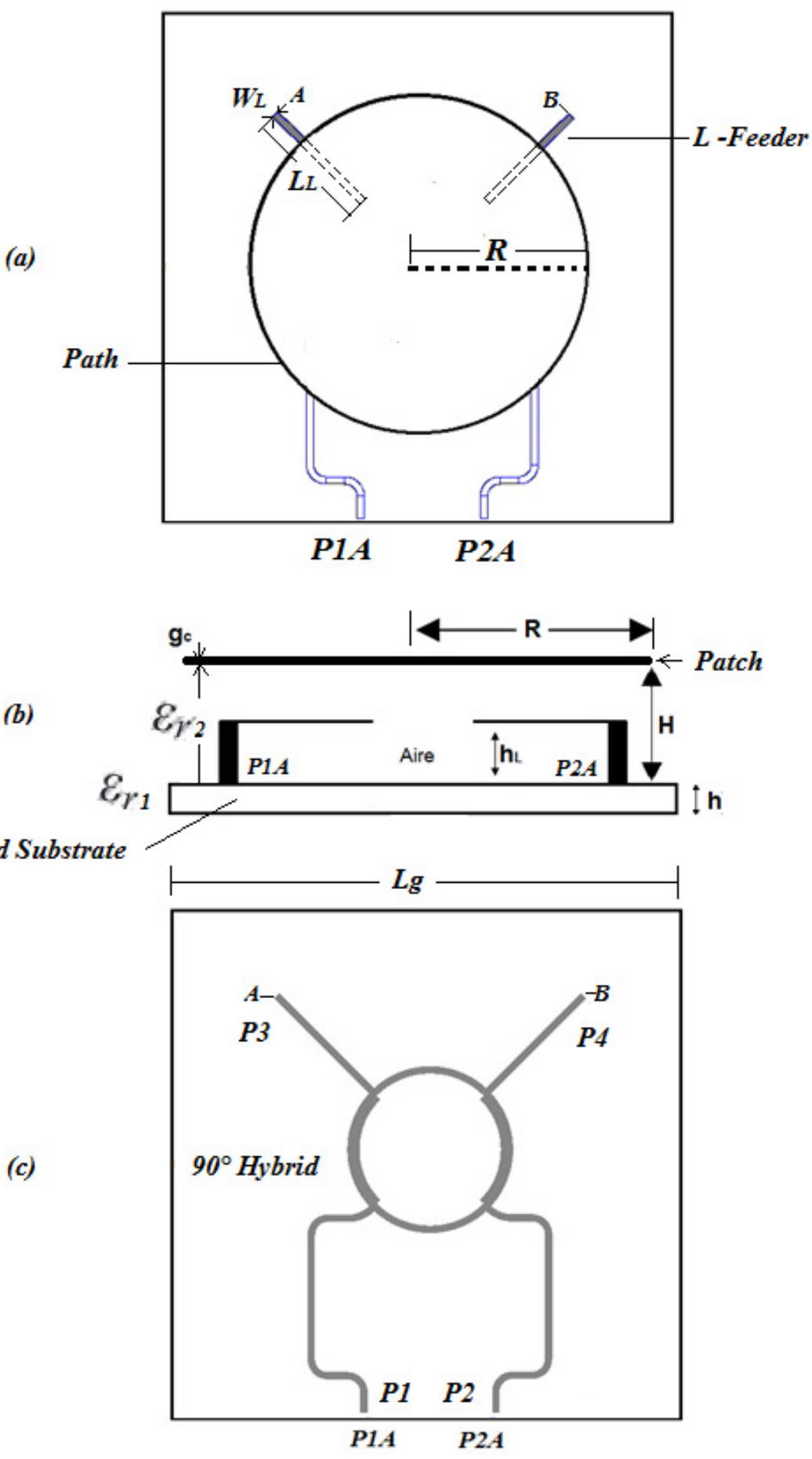

Fig. 1. Antenna geometry with L-shaped probe feeders and suspended circular patch: a) Top view b) Side view c) Bottom view: Geometry of the hybrid coupler including ports P1 to P4. Source: Authors. 
The substrate used for the design of the hybrid coupler has a dielectric constant $\varepsilon_{\mathrm{r} 1}=3.5$, a loss tangent of $\operatorname{Tan} \delta=0.0018$ and a thickness of $h=0.508 \mathrm{~mm}$. The L shape probe feeders are separated by an angle of $90^{\circ}$ built on copper foil with a thickness of $g_{c}=0.5 \mathrm{~mm}$. To suspend the circular patch on the substrate, holes are made in the patch and the substrate and nylon screws and nuts are fixed, thereby allowing to control the total separation $\mathrm{H}$ between the patch and the substrate to the required values. The change in the direction of rotation of the circular polarization RHCP to LHCP and vice versa is achieved by exchanging the connection of the RF signal to one of the input ports of the hybrid coupler,

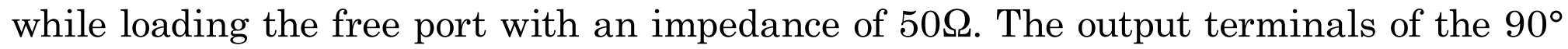
hybrid coupler are connected to the two L shape probes located below the circular patch by means of two vertical sections $h_{L}$ and horizontal (Fig. 1).

\section{A. Antenna design and parametric analysis}

As mentioned above, the design of the antenna uses (1)-(2) by which the radius of the circular patch $\mathrm{R}$ that includes the edge effects is determined [1]-[2].

$$
R=F /\left\{1+\frac{2 H}{\pi \epsilon_{r 2} F}\left[\ln \left(\frac{\pi F}{2 H}\right)+1.7726\right]\right\}^{1 / 2}
$$

Where $H$ is the separation between the ground plane and the circular patch, $\varepsilon_{r 2}$ is the dielectric constant, which is taken as $\varepsilon_{r 2}=1$ (air) and $\mathrm{F}$ is defined in terms of the resonance frequency and the dielectric constant as (2):

$$
F=8.791 \times 10^{9} / f_{r} \sqrt{\epsilon_{r 2}}
$$

The design of the initial geometry of the antenna with center frequency at $f_{r}=$ $2.4 \mathrm{GHz}$, begins with the circular patch design using (1)-(2), thus, an initial radius for the circular patch of $R=30 \mathrm{~mm}$ is calculated by means of the experimental study presented by [12] for antennas with rectangular geometry, single-port L-shape probe and linear polarization. The remaining parameters of the geometry are determined in wavelengths as follow: Height between the ground plane and the suspended patch of $\mathrm{H}=0.099 \lambda_{0} \quad(H=12 \mathrm{~mm})$, the height of the feeders relative to the substrate of $h_{L}=0.066 \lambda_{0}\left(h_{L}=8.2 \mathrm{~mm}\right)$, the length of the feeder section parallel to the patch $L_{L}=$ $20 \mathrm{~mm}$, and the feeder width $w_{L}=1.0 \mathrm{~mm}$.

Fig. 2 shows the simulations results for the reflection coefficient magnitude for this initial design. The results show that the geometry requires to be optimized since its resonance turns out to be close to the $-10 \mathrm{~dB}$ reference, with a reduced bandwidth where its lower cut-off frequency is $f_{L}=2.18 \mathrm{GHz}$ and the upper cut-off frequency is $f_{H}=2.56 \mathrm{GHz}$.

Antenna optimization was carried out by means of parametric analysis performed on the aforementioned antenna geometric parameters as follow: separation between the substrate (printed hybrid) and the patch $(\mathrm{H})$, radius of the circular patch (R), parallel length of the $\mathrm{L}$ shape probe $\left(L_{L}\right)$, length of the vertical section of the $\mathrm{L}$ shape probe $\left(h_{L}\right)$ and width of this $\left(W_{L}\right)$ verifying their effects on the electromagnetic behavior of the antenna, namely impedance and axial ratio bandwidths, the radiation pattern, the gain and the central resonance frequency, all of which are associated with the resulting total size of the antenna.

In this sense, several simulations were carried out in which the length of the vertical section of the feeder $\left(h_{L}\right)$ is changed in the range of $2 \mathrm{~mm} \leq h_{L} \leq 10 \mathrm{~mm}$, and the length of it $\left(L_{L}\right)$ in the range of $18 \mathrm{~mm} \leq L_{L} \leq 34 \mathrm{~mm}$, the results of the parametric analyzes are shown below. 


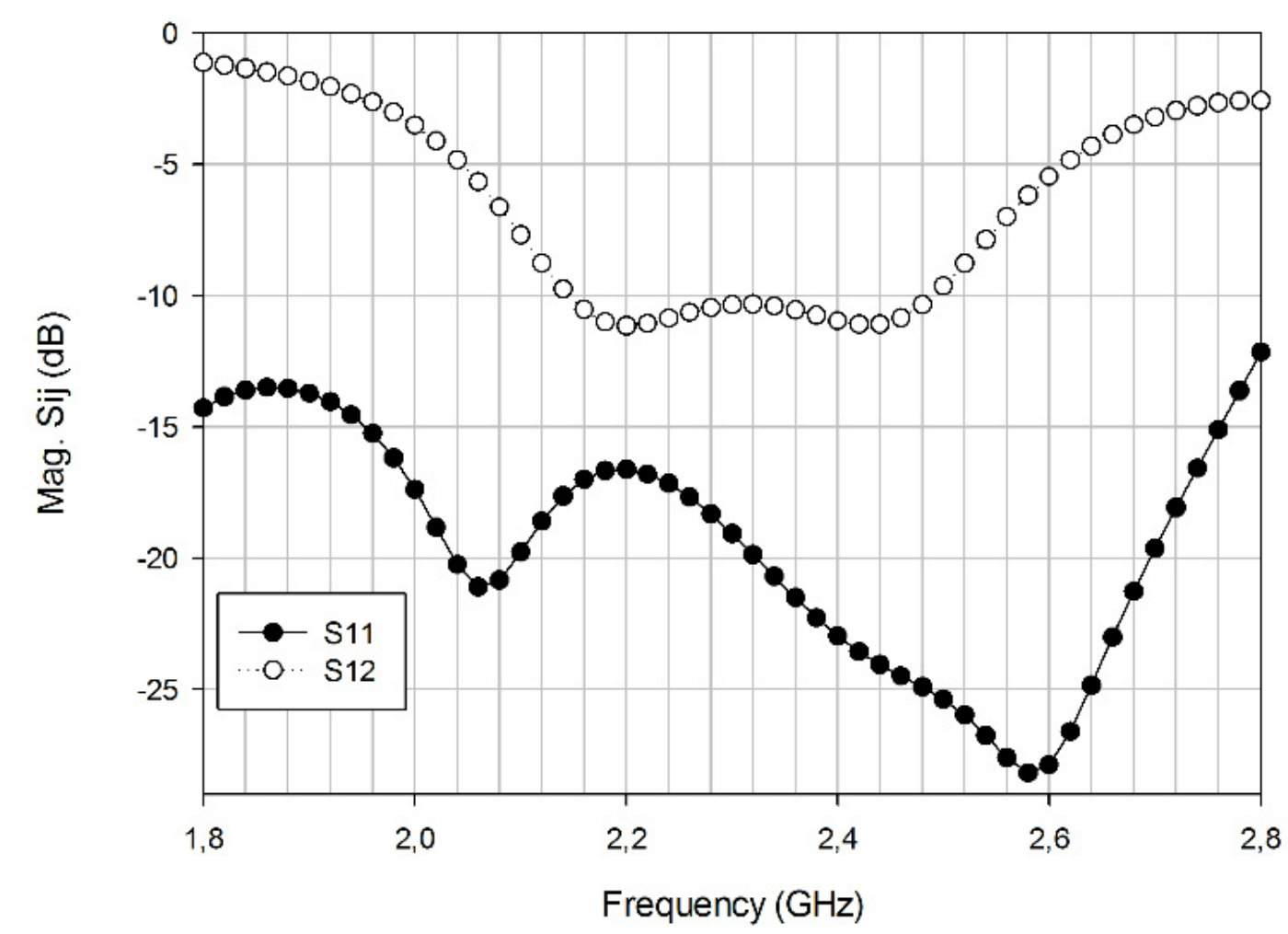

Fig. 2. Reflection coefficient magnitude for initial design. Source: Authors.

Fig. 3 shows simulation results of the reflection coefficient magnitude at port $1\left(S_{11}\right)$ and coupling between ports 1 and $2\left(S_{12}\right)$ in three of the best cases when varying the parallel length $\left(L_{L}\right)$ and the vertical length of the feeder $\left(h_{L}\right)$ for the following sets of values: $L_{L}=28 \mathrm{~mm}$, $h_{L}=4 \mathrm{~mm}, L_{L}=30 \mathrm{~mm}, h_{L}=4 \mathrm{~mm}$, and $L_{L}=32 \mathrm{~mm}$ y $h_{L}=6 \mathrm{~mm}$. As a result of the previous analysis we conclude that the set of values that yield the best results are: $L_{L}=28 \mathrm{~mm}$ y $h_{L}=4.5 \mathrm{~mm}$, for a width of then of $W_{L}=1.1 \mathrm{~mm}$.

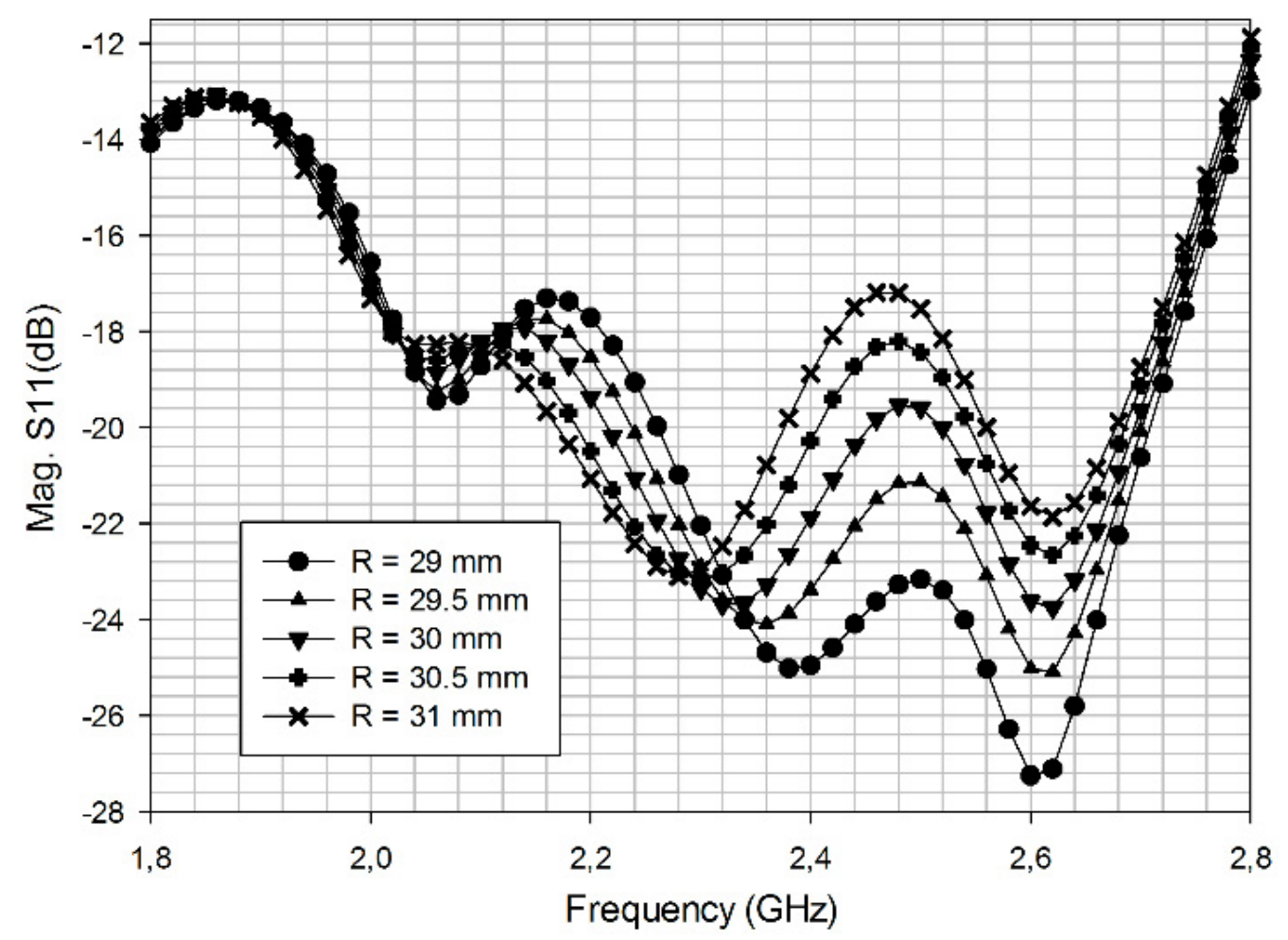

Fig. 3. Reflection coefficient $\left(S_{11}\right)$ and coupling coefficient $\left(S_{12}\right)$ versus parallel length $\left(L_{\mathrm{L}}\right)$. and vertical length $\left(h_{\mathrm{L}}\right)$. Source: Authors.

In the same way, Fig. 4 shows simulation results of the reflection coefficient magnitude at port $1\left(S_{11}\right)$ for five different values of the circular patch radius $\mathrm{R}$ (parameter $\mathrm{R}$ in Fig. 1 ), for variations of this parameter between $R=29 \mathrm{~mm}$ and $R=31 \mathrm{~mm}$ maintaining the distance $H=12 \mathrm{~mm}$, the parallel length of the feeder $\left(L_{L}=28 \mathrm{~mm}\right)$, the length of the vertical section $\left(h_{L}=4.5 \mathrm{~mm}\right)$ and width of the feeder $\left(W_{L}=1.1 \mathrm{~mm}\right)$. As observed, the port adaptation and impedance bandwidth are greater than $1 \mathrm{GHz}$ and slightly depends on this parameter $(\mathrm{R})$ and its value is always less than $-10 \mathrm{~dB}\left(S_{11}<-10 \mathrm{~dB}\right)$. 


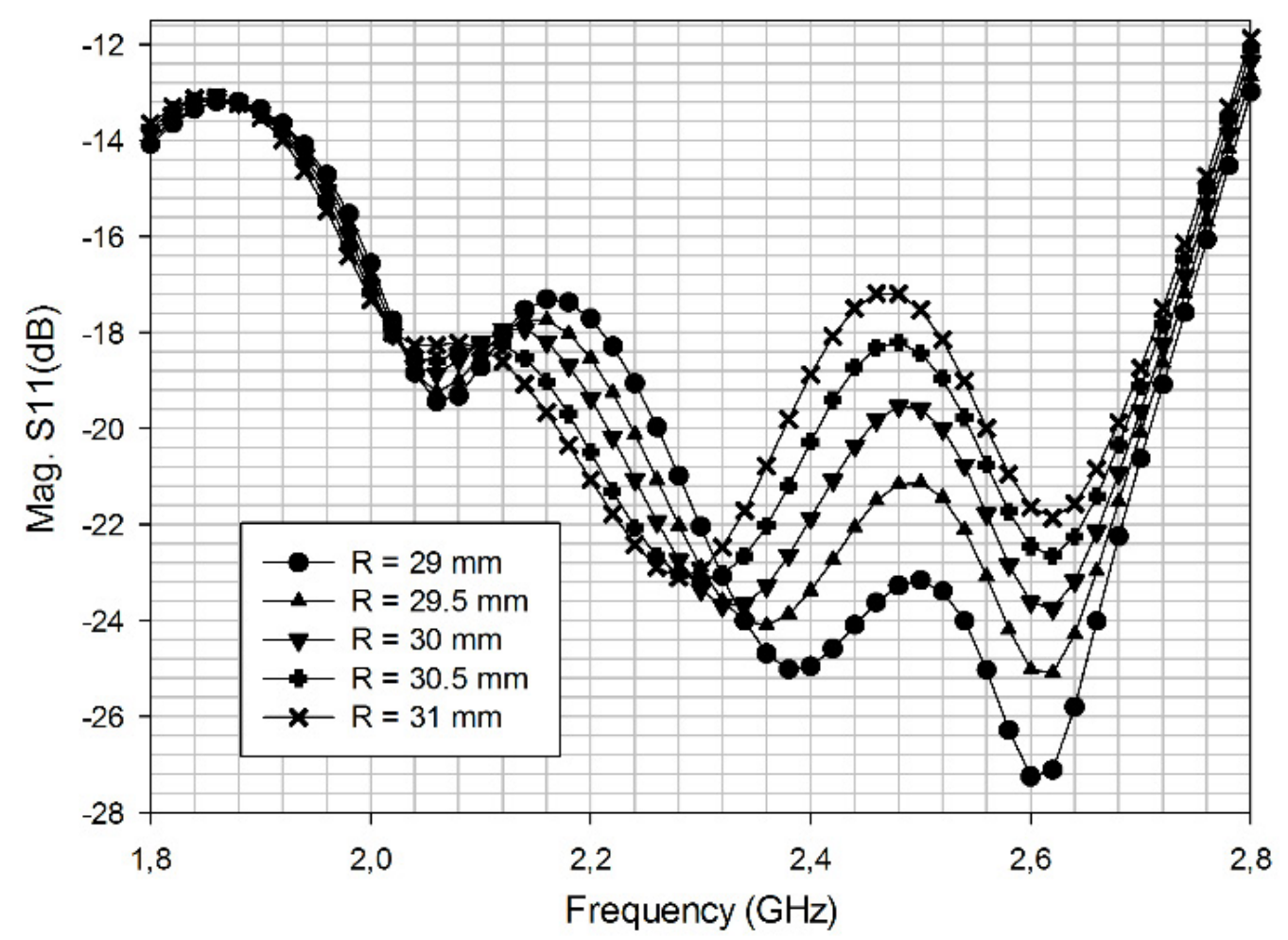

Fig. 4. Reflection coefficient $\left(S_{11}\right)$ versus five Radius $(R)$. Source: Authors.

On the other hand, Fig. 5 shows the behavior of the coupling parameter between the two input ports of the antenna $\left(S_{12}\right)$ versus the size of the patch radius $(\mathrm{R})$. As opposed to the previous case, the coupling bandwidth between the ports in the five cases analyzed is close to $400 \mathrm{MHz}$. Further analysis will focus on improving the bandwidth of this parameter.

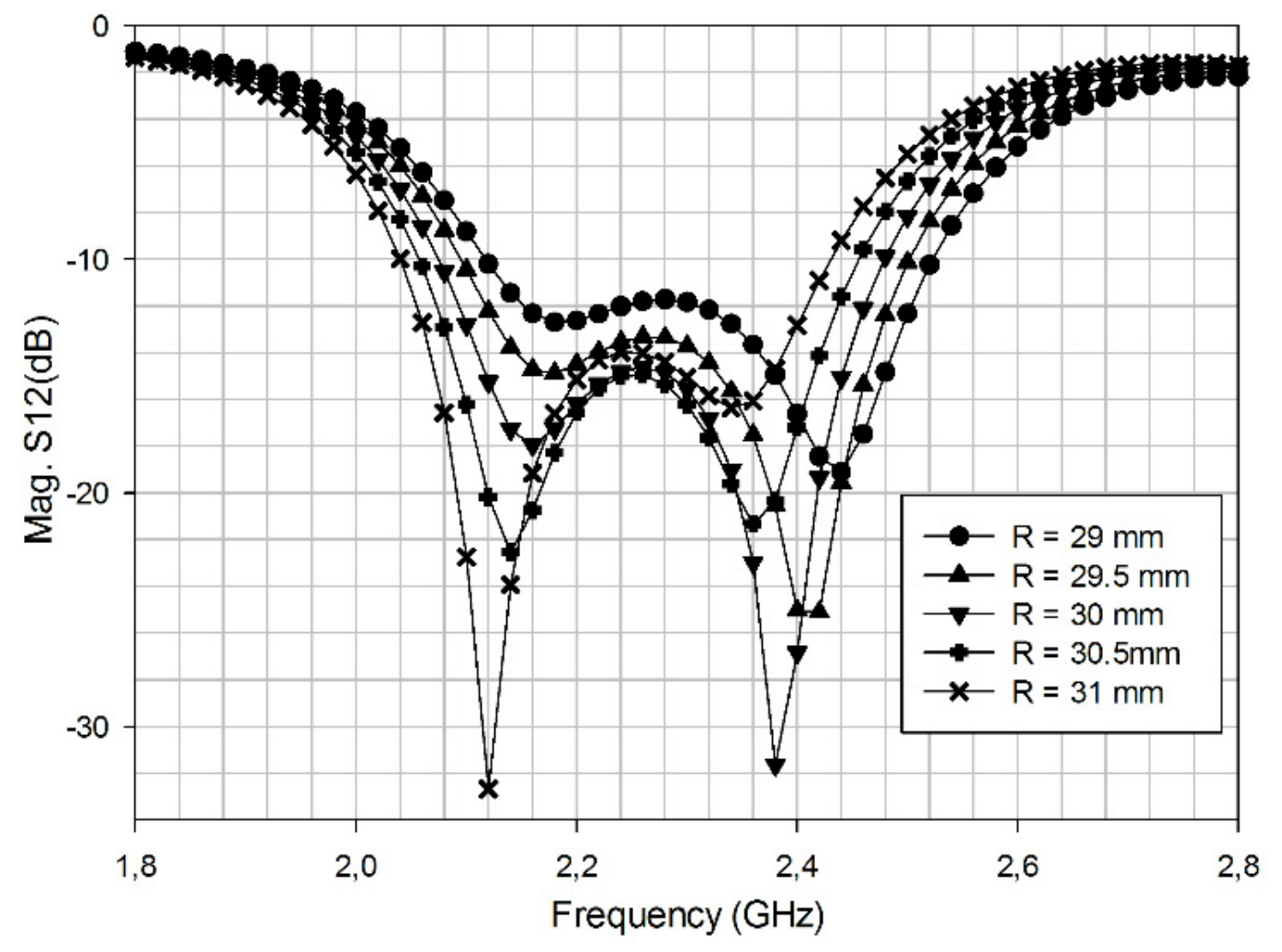

Fig. 5. Behavior of the coupling parameter $\left(S_{12}\right)$ versus patch radius $(\mathrm{R})$. Source: Authors.

Fig. 6 shows the behavior of antenna gain bandwidth for five different radius (R) sizes. As shown in the Fig. 6, the maximum gain of the antenna is $8.3 \mathrm{dBi}$ and its bandwidth for a reference of $-1 \mathrm{dBi}$ is in the order of $480 \mathrm{MHz}$ with a shift of the center frequency to the right as the radius of the circular patch is reduced as expected. 


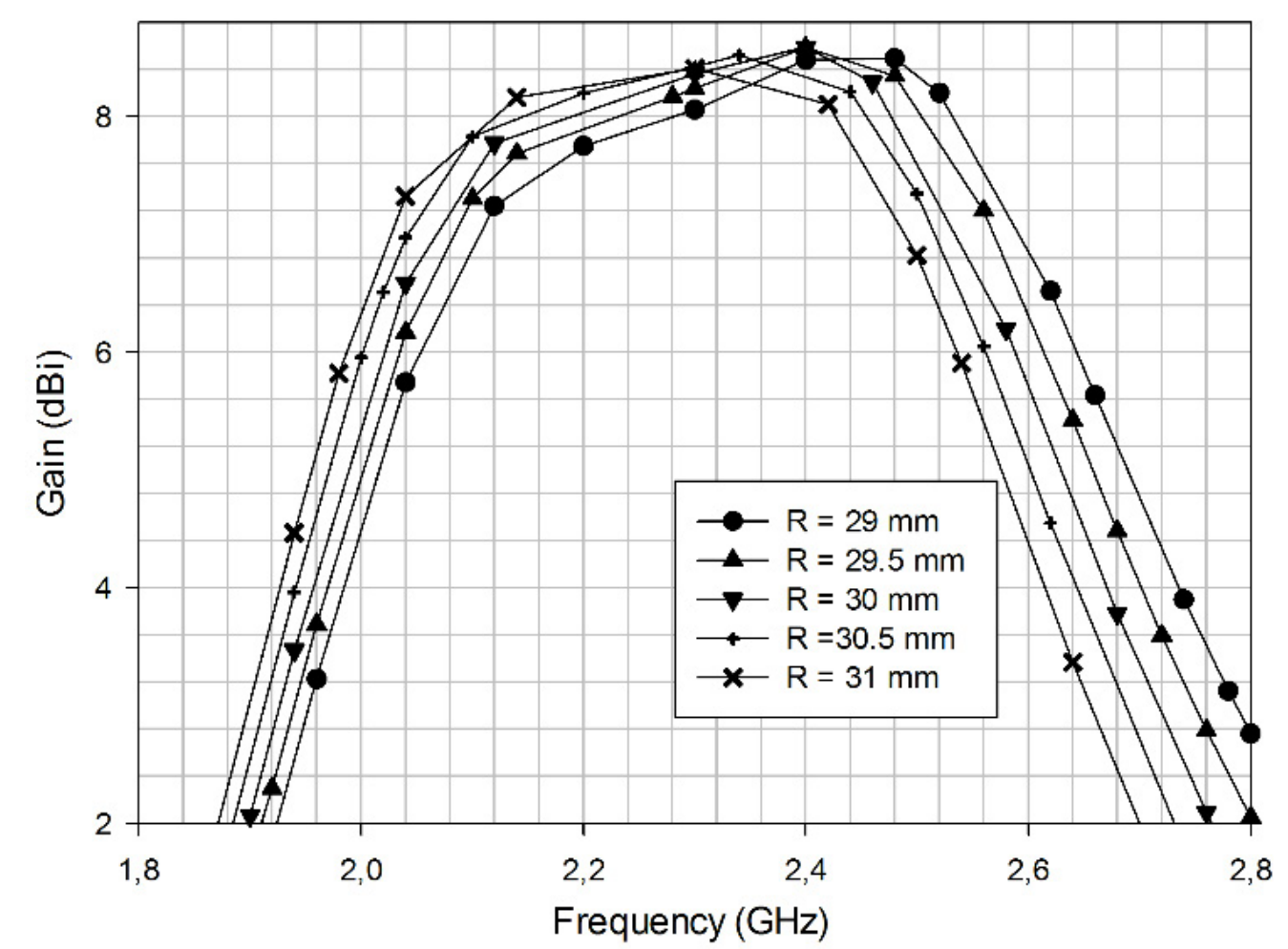

Fig. 6. Behavior of antenna gain bandwidth for five different radius (R). Source: Authors.

Fig. 7 shows the behavior of the coupling between the ports $\left(S_{12}\right)$ versus the distance $\mathrm{H}$ ranging from $H=8 \mathrm{~mm}$ to $H=12 \mathrm{~mm}$ to and maintaining fixed the other parameters as: $R=29 \mathrm{~mm}$, the parallel length of the feeder $\left(L_{L}=28 \mathrm{~mm}\right)$, the length of the vertical section $\left(h_{L}=4.5 \mathrm{~mm}\right)$ and the feeder width of $\left(W_{L}=1.1 \mathrm{~mm}\right)$. As observed, this parameter $\left(S_{12}\right)$ deteriorates as the distance $\mathrm{H}$ decreases.

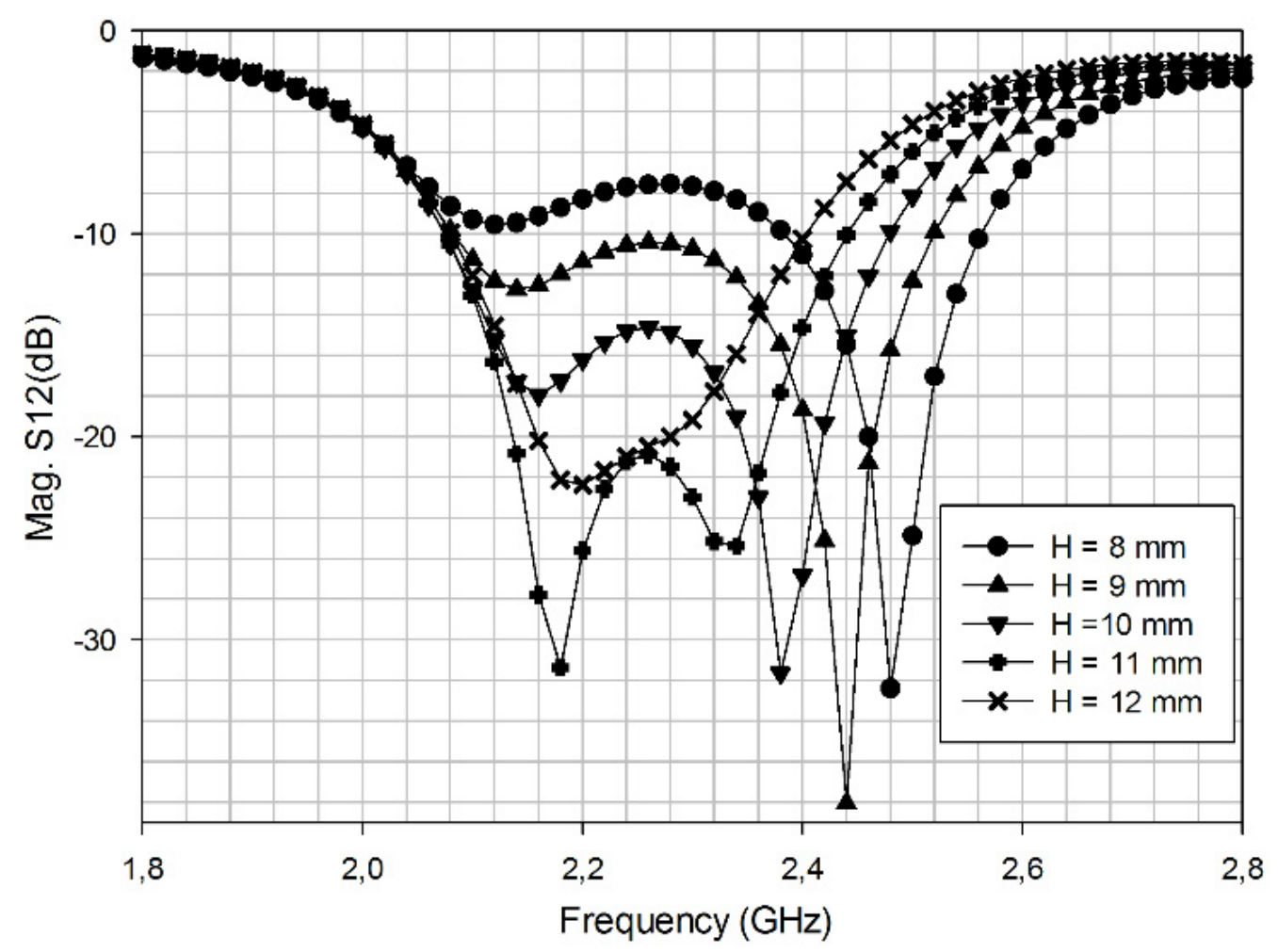

Fig. 7. Coupling between the ports $\left(S_{12}\right)$ versus the distance $H$ for variations of this length between $H=8 \mathrm{~mm}$ and $H=12 \mathrm{~mm}$. Source: Authors.

Likewise, in Fig. 8 the behavior of the axial ratio bandwidth is analyzed for a reference of $3 \mathrm{~dB}$ versus different values of the separation $\mathrm{H}$, while maintaining fixed the other parameters associated with the antenna geometry like: $R=29 \mathrm{~mm}$, the parallel length of the feeder $\left(L_{L}=28 \mathrm{~mm}\right)$, the length of the vertical section $\left(h_{L}=4.5 \mathrm{~mm}\right)$ and the feeder width of $\left(W_{L}=1.1 \mathrm{~mm}\right)$. 


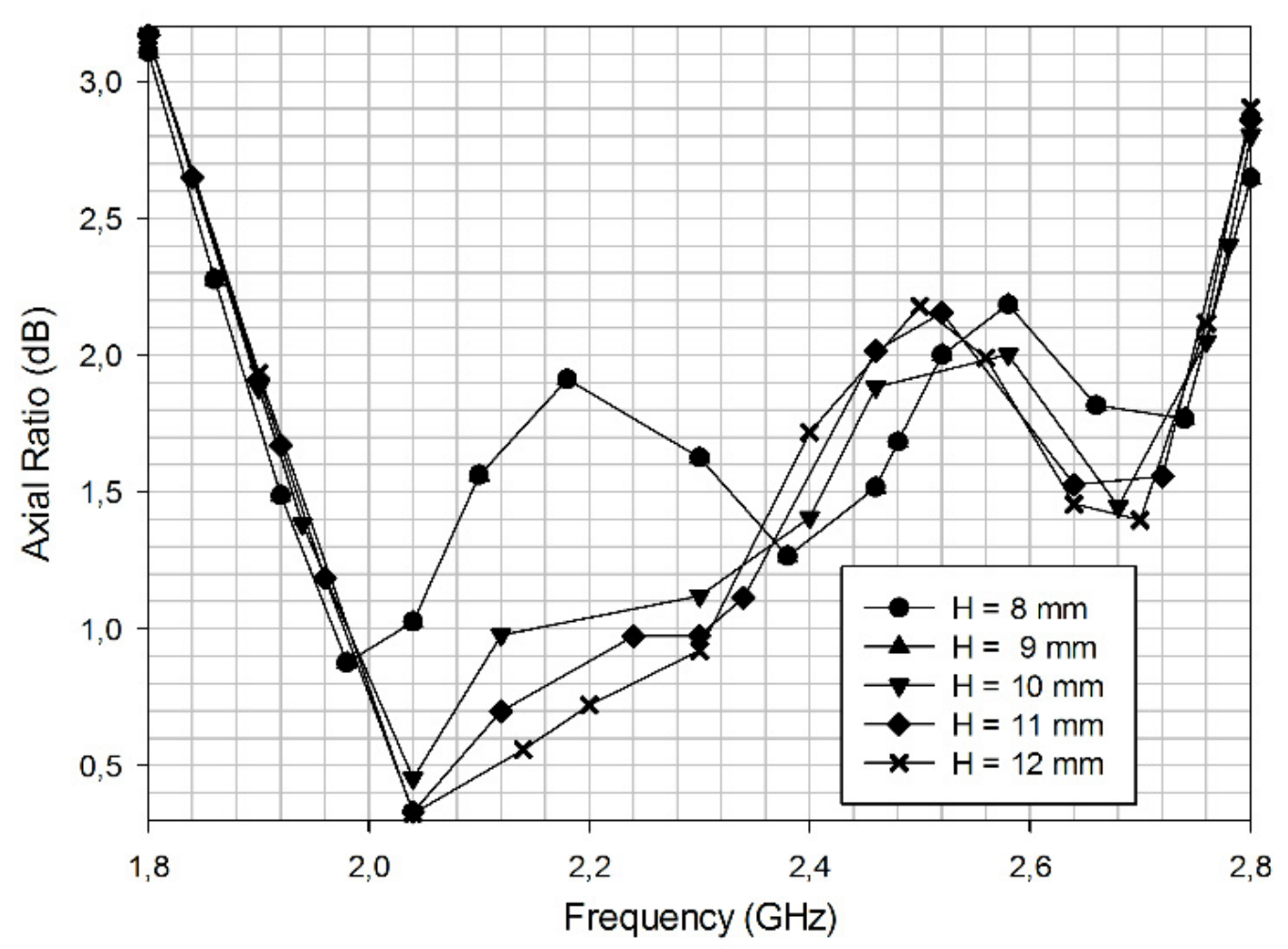

Fig. 8. Axial ratio bandwidth for a reference of $3 \mathrm{~dB}$, versus the $H$-separation between $H=8 \mathrm{~mm}$ and $H=12 \mathrm{~mm}$.

Source: Authors.

In this sense, from Fig. 8 it is noted that for the separations of $H=8 \mathrm{~mm}$ and $9 \mathrm{~mm}$, the axial ratio behavior is similar, but when the height is $H=10 \mathrm{~mm}$, it is reduced to values around $1 \mathrm{~dB}$ for a frequency near to 2.2GHz. Furthermore, in Fig. 8 it follows that in the range of interest for the $\mathrm{H}$-separation; this length does not affect the axial ratio bandwidth, even though some critical points are evident.

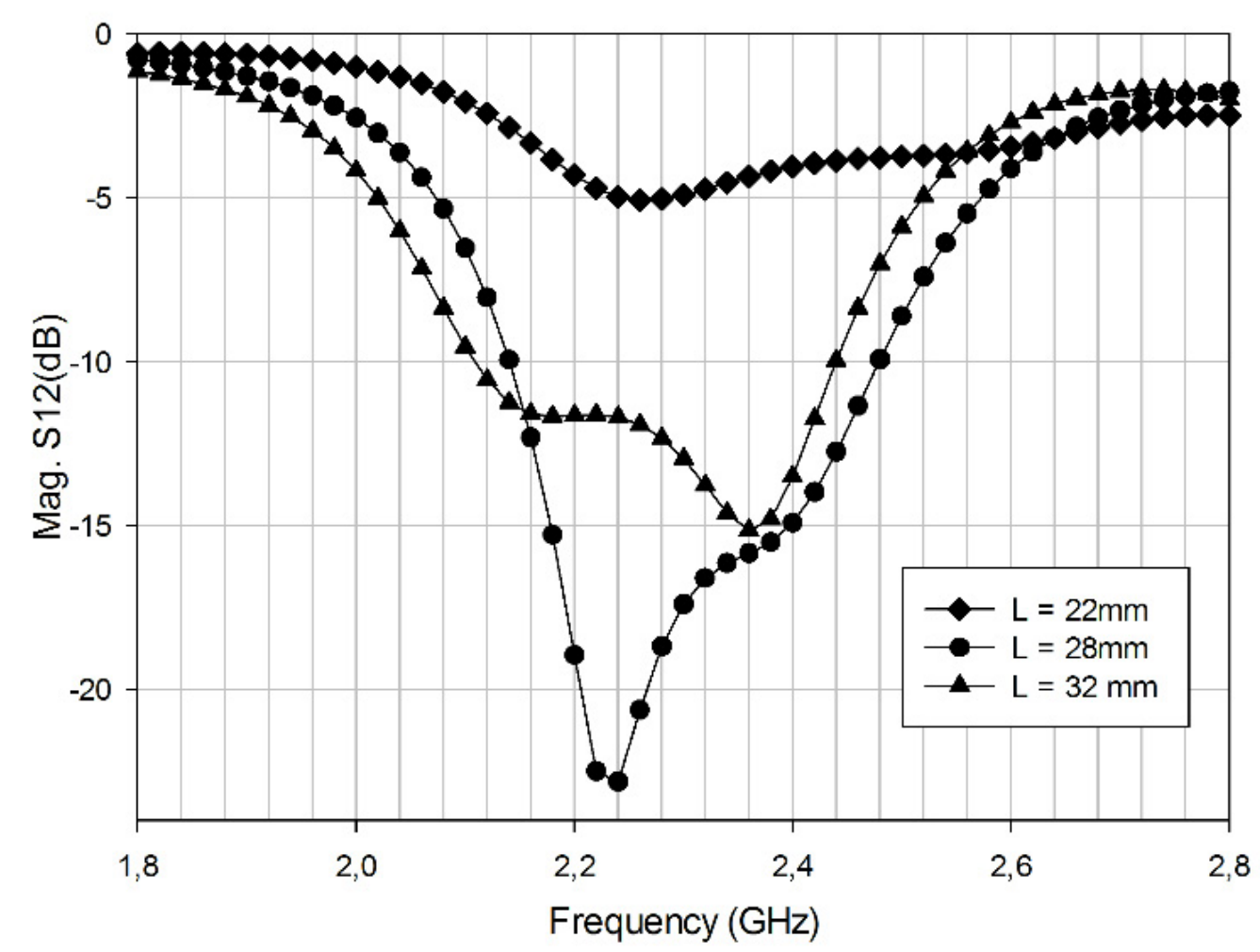

Fig. 9. Simulations results for the effect of the horizontal section length of the feeder $\left(L_{L}\right)$ versus the coupling between ports $\left(S_{12}\right)$. Source: Authors.

Finally, it is desired to reduce the coupling between ports to $S_{12} \leq-15 \mathrm{~dB}$, in that sense, Fig. 9 shows the simulations results for the effect of the horizontal section length of the feeder $\left(L_{L}\right)$ versus the coupling between ports $\left(S_{12}\right)$, for three lengths of this parameters namely: $L_{L}=$ $22 \mathrm{~mm}, L_{L}=28 \mathrm{~mm}$ and $L_{L}=32 \mathrm{~mm}$; maintaining fixed the other parameters in the dimensions established in the previous paragraph. 


\section{B. Hybrid coupler design}

The design of the $90^{\circ}$ hybrid coupler makes use of the model proposed [20] and its input and output ports are appropriately located to meet the requirements of the antenna geometry. The initial basic model is designed for a central frequency of $2.4 \mathrm{GHz}$ to be further optimized by parametric analyzes carried out on the lengths and widths of each of these transmission lines. The optimization was carried out using commercial software for analysis of microwave circuits and its geometry is shown in Fig. 1(c).

Fig. 10 shows the simulated results for the most important dispersion parameters, namely: adaptation of port $1\left(S_{11}\right)$, transmission between ports 1 and $2\left(S_{12}\right)$ and coupling between ports 2 and $3\left(S_{23}\right)$. Similarly, Fig. 11 shows the phase difference between parameters $S_{12}$ and $S_{13}$. As can be deduced from these simulations, the adaptation, transmission and coupling parameters exhibit appropriate simulation results, particularly transmission $\left(S_{12}\right)$ levels have -3dB at the center frequency of $2.4 \mathrm{GHz}$, and a phase difference of $90^{\circ}$ between the parameters $S_{12}$ and $S_{13}$ to the frequency $2.4 \mathrm{GHz}$.

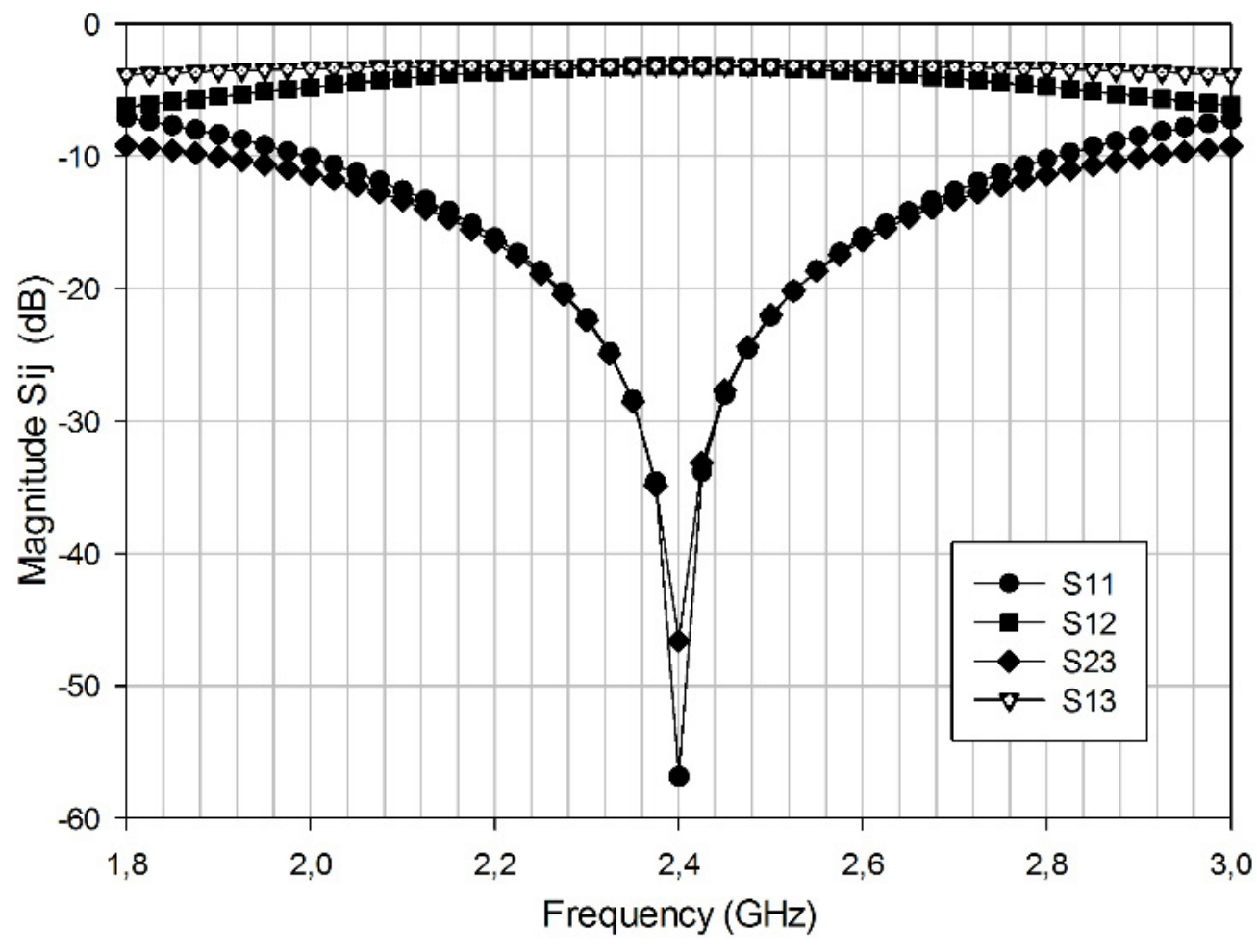

Fig. 10. Simulated results for dispersion parameters $\left(S_{11}\right),\left(S_{12}\right),\left(S_{23}\right)$ and $\left(S_{13}\right)$. Source: Authors.

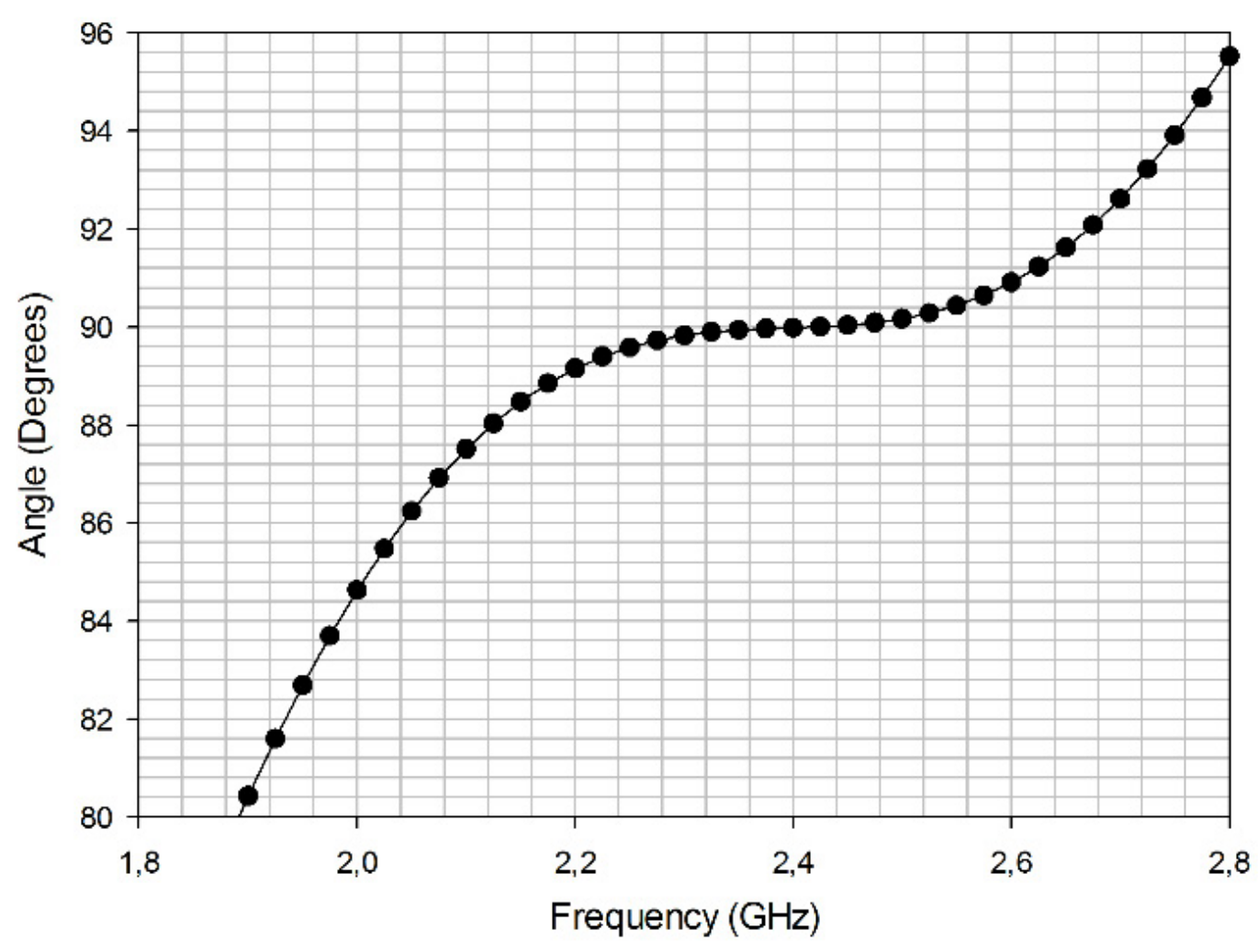

Fig. 11. Phase difference between and transmission parameters. Source: Authors. 
In the coupler design process, special attention was paid to the aforementioned parameters, taking into account that their appropriate behavior allows the antenna to operate in circular polarization by guaranteeing excitation levels of similar values at each antenna input port and one phase difference of $90^{\circ}$ between the two ports, which ultimately allows to improve the axial ratio of the antenna.

Once the independent design of both antenna and the hybrid coupler was completed they were integrated. For this purpose, simulations of the complete set were carried out until the desired behavior was achieved as shown in the following section.

The final dimensions of the proposed antenna in this work are: disc radius $R=30 \mathrm{~mm}$, feeder width $w_{L}=1.11 \mathrm{~mm}$, feeder height $h_{L}=4.5 \mathrm{~mm}$, feeder length $L_{L}=28 \mathrm{~mm}$, separation between disc and substrate $H=10 \mathrm{~mm}$, substrate thickness $h=0.508 \mathrm{~mm}$, copper disk thickness $g_{c}=0.5 \mathrm{~mm}$, side of the square ground plane: $L_{g}=80 \mathrm{~mm}$.

\section{RESUlTS AND ANALYsis}

Based on the antenna model designed and optimized in the previous sections, a prototype is developed to validate the proposal by means of the impedance characterization using a Rohde \& Schwartz ZVL13 vector network analyzer and the anechoic chamber pattern characterization. Fig. 12 shows the photo of the front view of the antenna once finished its manufacture and assembly including the SMA connectors.

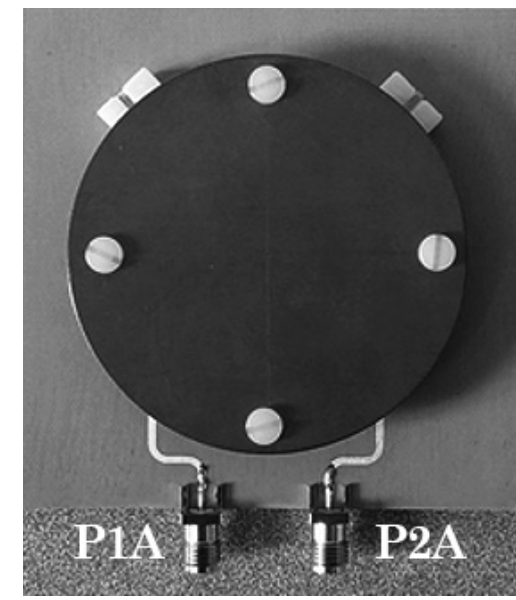

Fig. 12. Photographs of the front view of the antenna. Source: Authors.

Fig. 13 shows the measurements results of the reflection coefficient magnitude at the port P1A $\left(S_{11}\right)$ for the fabricated prototype, compared to simulations results of the optimized model. As shown in the figure, the measurements results are similar to the simulation results. It is also observed that the antenna has an impedance bandwidth of $34.39 \%$ in the range of for reflection coefficient magnitude of $S_{11}<-10 \mathrm{~dB}$.

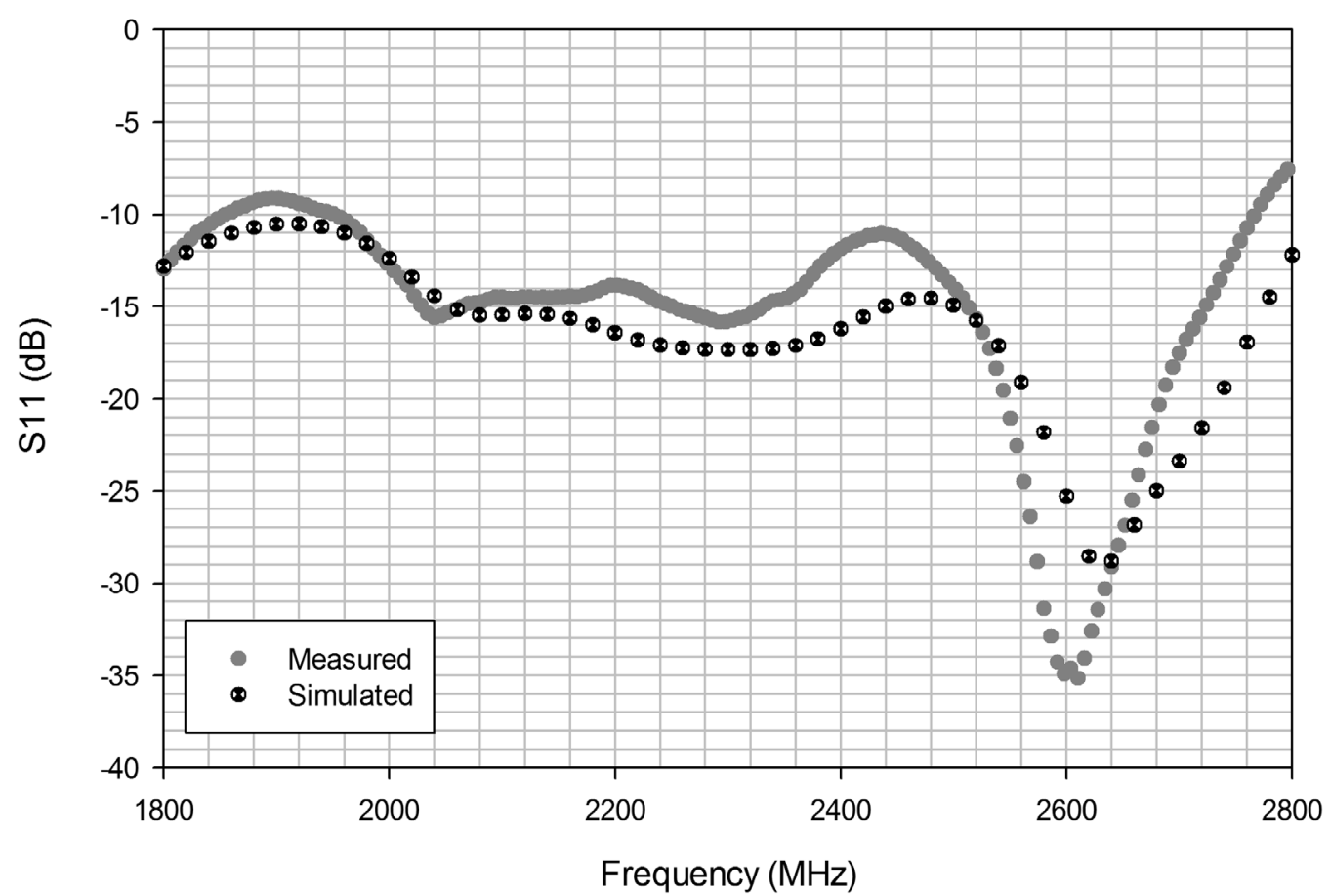

Fig. 13. Measurements results of the reflection coefficient magnitude at the port P1A $\left(S_{11}\right)$ for the fabricated prototype, compared to simulations results of the optimized model. Source: Authors. 
Likewise, Fig. 14 shows the measurements results of the reflection coefficient magnitude at P2A port $\left(S_{22}\right)$ for the fabricated prototype, compared to the results of the optimized model simulations. In this case it is observed that the antenna has an impedance bandwidth of in the range of $1.986 \mathrm{GHz}$ to $2.79 \mathrm{GHz}$ for a reflection coefficient magnitude of $S_{22}<-10 \mathrm{~dB}$.

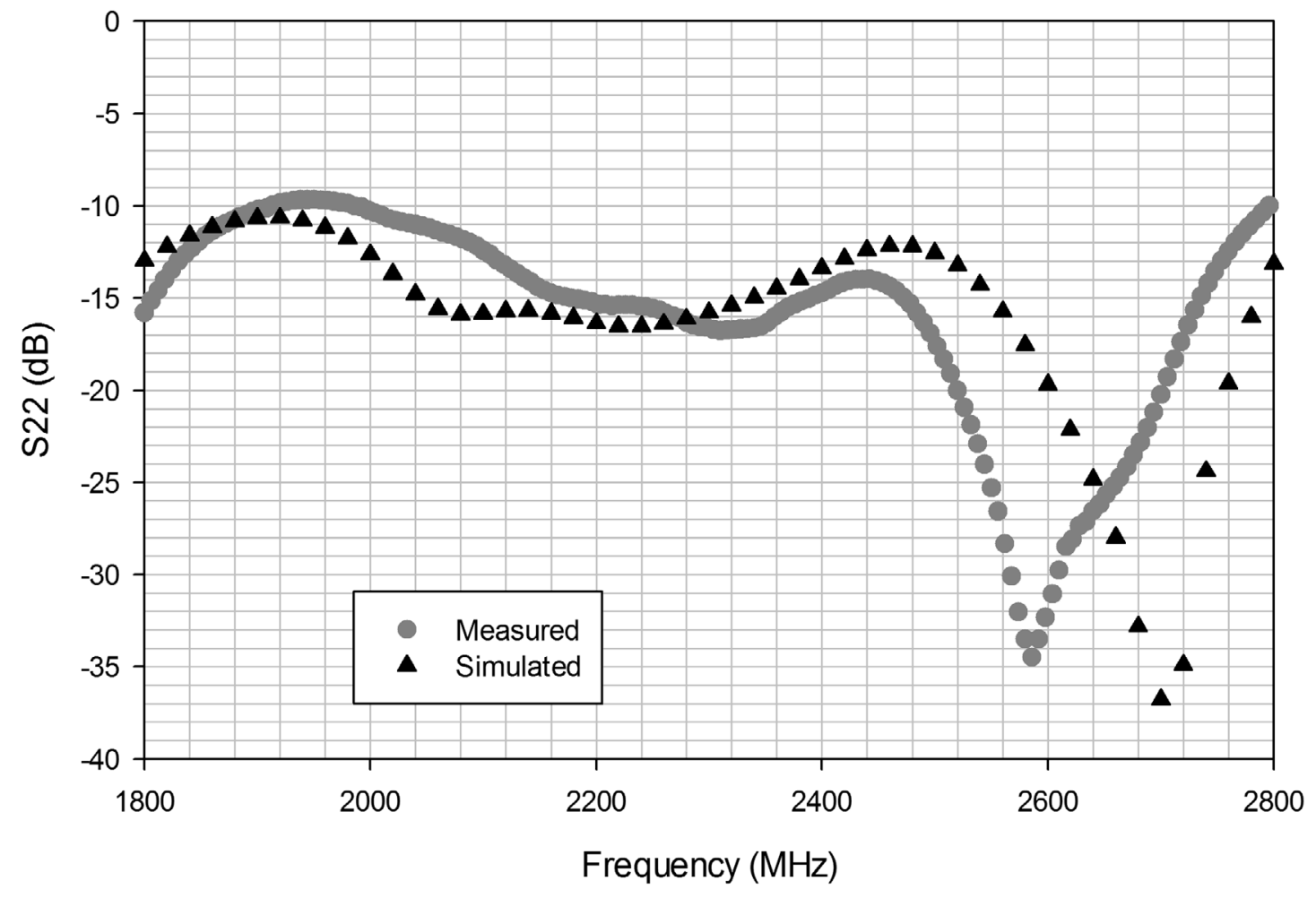

Fig. 14. Measurement results of the reflection coefficient magnitude at P2A port $\left(S_{22}\right)$ for the fabricated prototype, compared to the results of the optimized model simulations.

Source: Authors.

On the other hand, Fig. 15 shows the coupling measurements results between the two ports $\left(S_{21}\right)$, versus simulations results. As shown in the figure, the measurements of this parameter performed better than the simulations, with values lower than $S_{21}<-15 \mathrm{~dB}$ in the range of $2.3 \mathrm{GHz}$ to $2.44 \mathrm{GHz}$.

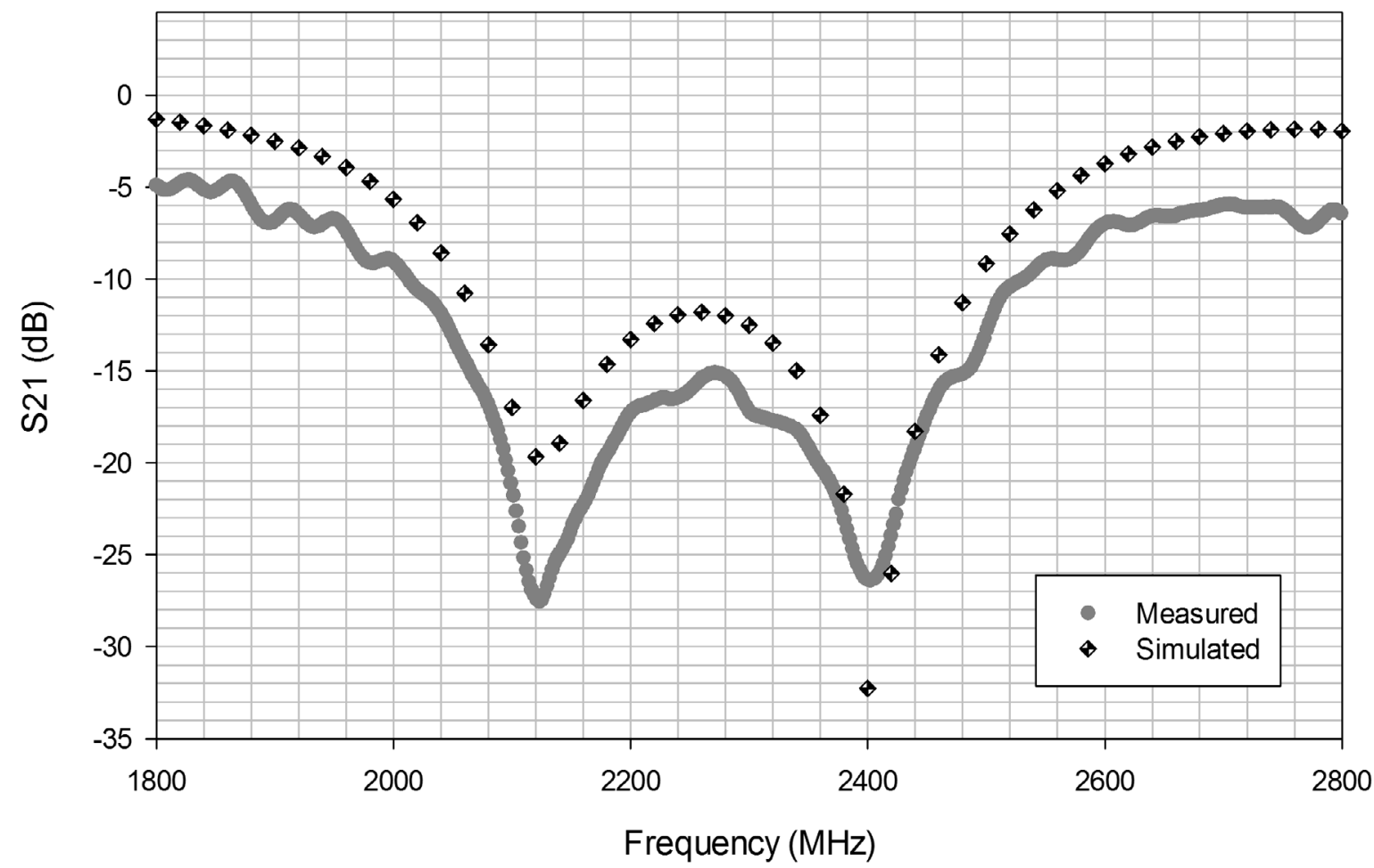

Fig. 15. Coupling measurements results between the two ports $\left(S_{21}\right)$, versus simulations results. Source: Authors.

In terms of the radiation pattern measurements, Fig. 16 shows the antenna gain measurement results versus the simulations. From this figure we can see the similarity of these results, on the other hand, the maximum gain obtained was $8.75 \mathrm{dBi}$ at a frequency of 2.35 $\mathrm{GHz}$. 


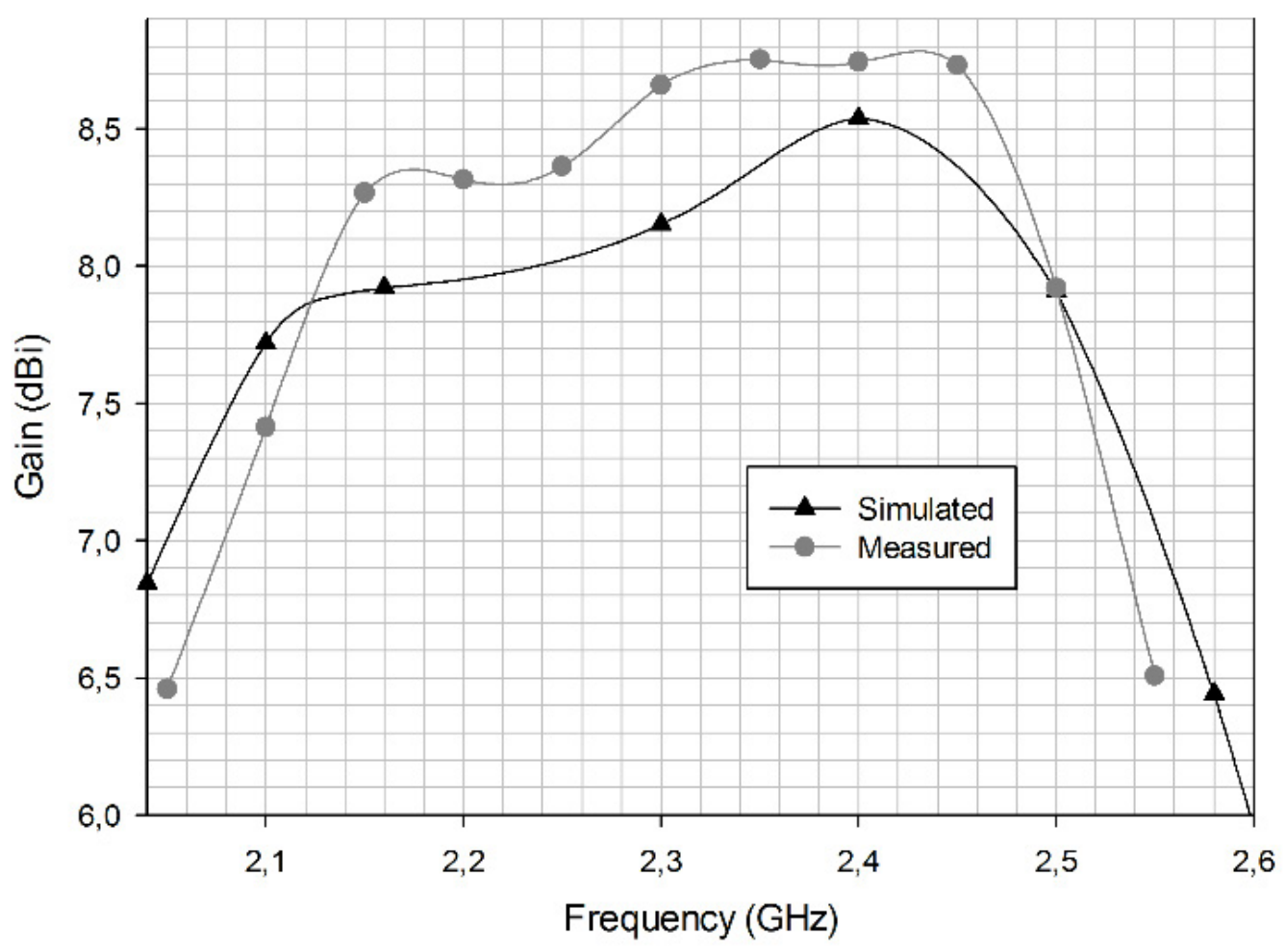

Fig. 16. Antenna gain measurement results versus simulations Source: Authors.

Fig. 17 shows the radiation pattern measurements results into anechoic chamber for the XY plane versuvs the simulation results obtained at a central frequency of $2.35 \mathrm{GHz}$. The Fig. 17 shows the similarity of the measured patterns against the simulated ones.

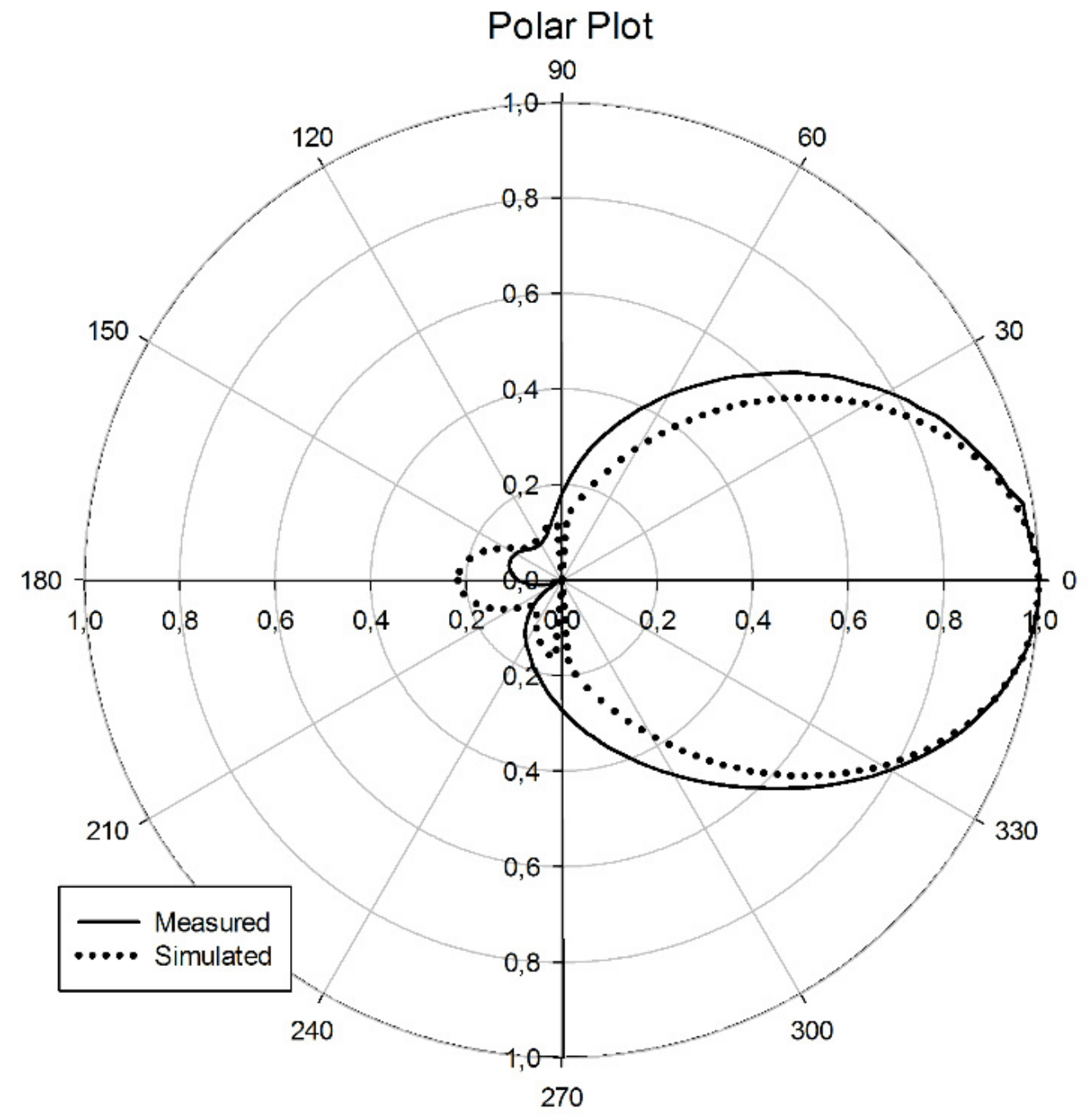

Fig. 17. Radiation pattern measurements results for the XY plane versus simulation results at $2.35 \mathrm{GHz}$. Source: Authors.

Finally, Fig. 18 shows the axial ratio simulation results, where it can be observed that in the frequency range of $1820 \mathrm{MHz}$ to $2800 \mathrm{MHz}$, the axial ratio is less than $3 \mathrm{~dB}$. 


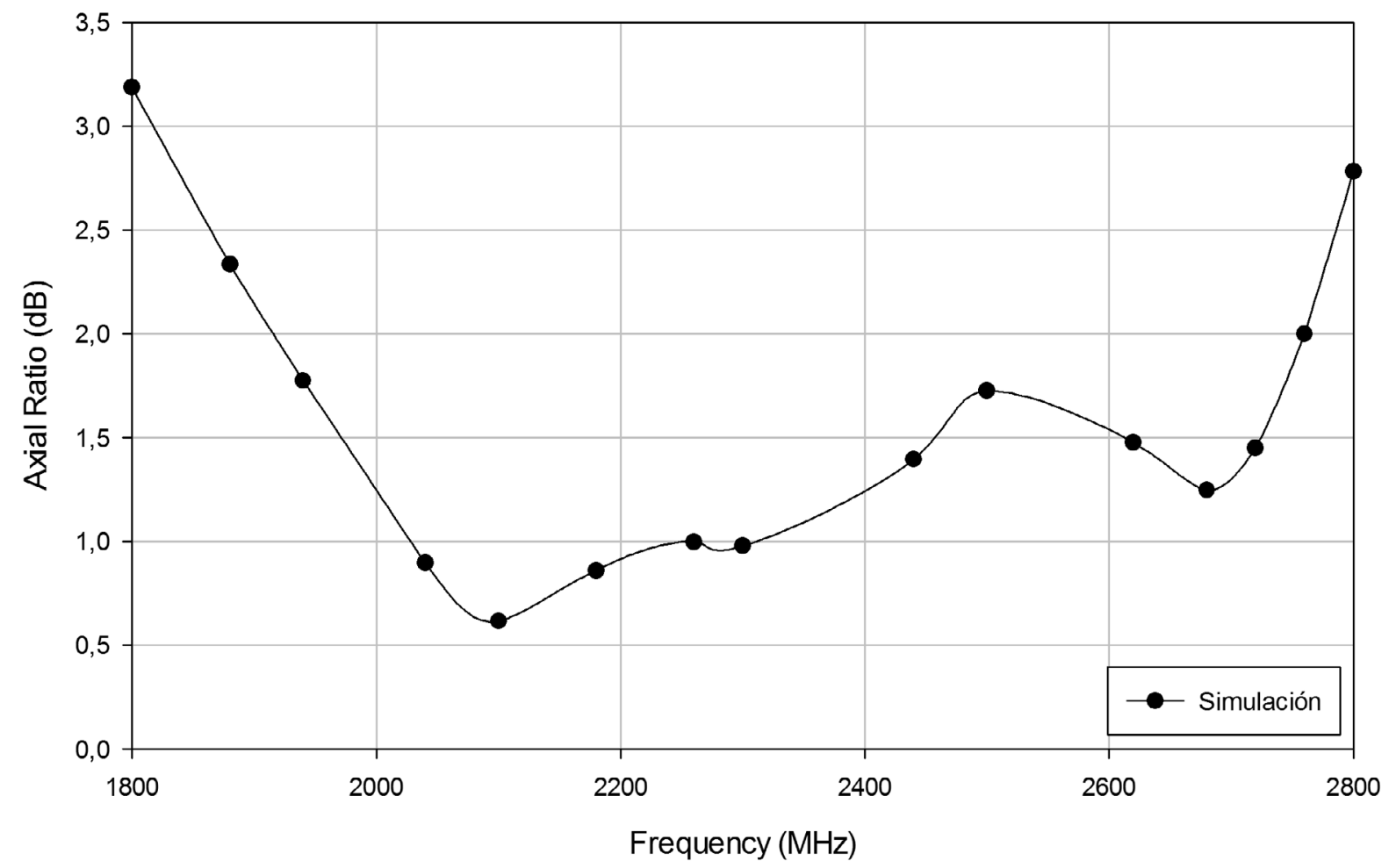

Fig. 18. Axial ratio simulation results. Source: Authors.

\section{Conclusions}

This paper presented the design and characterization of a circularly polarized antenna with interchangeable sense of rotation for small satellite applications, which consists of a circular suspended patch antenna fed by L-shaped probes through a $90^{\circ}$ hybrid coupler. The influence of all the geometric variables were investigated and optimized to obtain a maximum level of parameters such as maximum gain, axial ratio and impedance bandwidth. The proposal shows a maximum gain level of $8.75 \mathrm{dBi}$ at a frequency of $2.35 \mathrm{GHz}$; the simulated axial ratio is less than $3 \mathrm{~dB}$ in the frequency range of $1820 \mathrm{MHz}$ to $2800 \mathrm{MHz}$; and the impedance bandwidth for reflection coefficient magnitude of $S_{\mathrm{ii}}<-10 \mathrm{~dB}$ was $34.39 \%$ in the range of $1.95 \mathrm{GHz}$ a $2.76 \mathrm{GHz}$ for the $\mathrm{P} 1 \mathrm{~A}$ port and $33.66 \%$ in the range of $1.986 \mathrm{GHz}$ to $2.79 \mathrm{GHz}$ for the $\mathrm{P} 2 \mathrm{~A}$ port. From the obtained results it is concluded that the L-shaped probes technique for suspended patches improves the behavior of the antenna in both impedance and maximum gain and axial ratio response. On the other hand, the simulations results against the experimental measurements presented a similar behavior, this fact enables the use of the proposed method to design antennas operating at different frequencies than those demonstrated in this paper.

\section{REFERENCES}

[1] C. Balanis, Antenna Theory: Analysis and Design. New York, USA: Wiley, 2005.

[2] S. Gao, Q. Luo \& F. Zhu, Circularly polarized antennas. New York, USA: Wiley, 2014.

[3] K. Finkenzeller, RFID Handbook. Chichester, UK: Wiley, 2003. https://doi.org/10.1002/0470868023

[4] K. Girish Kumar, "Broadband Microstrip Antennas," in Compact and Broadband Microstrip Antennas, New York, USA: Wiley, 2003, pp. 232-278.

[5] H. Nakano, M. Yamazaki \& J. Yamauchi, "Electromagnetically coupled curl antenna," Electron. Lett., vol. 33, no. 12, p. 1003-1004, Jun. 1997. https://doi.org/10.1049/el:19970747

[6] C. Suárez, D. Méndez, A. Pineda \& G. Puerto, "Antena de parche con sentido de giro reconfigurable para aplicaciones en satélites CubeSat," DYNA, vol. 83, no. 199, p. 157-164, Oct. 2016. https://doi. org/10.15446/dyna.v83n199.52449

[7] C. Suárez, J. Carroll \& G. Puerto, "Antena Compacta para Aplicaciones en Satélites de Reducido Tamaño," Inf. tecnológica, vol. 27, no. 3, pp. 189-198, Jun. 2016. https://doi.org/10.4067/S071807642016000300018

[8] G. Suárez, C. López \& G. Puerto, "Antena plana para aplicaciones en las bandas L1 y L2 de GPS," Ing. y Desarro., vol. 34, no. 1, pp. 248-265, Jan. 2016. https://doi.org/10.14482/inde.34.1.7956

[9] L. Ge, C.-Y.-D. Sim, H.-L. Su, J.-Y. Lu \& C. Ku, "Single-layer dual-broadband circularly polarised annular-slot antenna for WLAN applications," IET Microwaves, Antennas Propag., vol. 12, no. 1, pp. 99-107, Sep. 2017. https://doi.org/10.1049/iet-map.2017.0203

[10] L. Zhang, S. Gao, Q. Luo, P. Young \& Q. Li, "Wideband Loop Antenna With Electronically Switchable Circular Polarization," IEEE Antennas Wirel. Propag. Lett., vol. 16, pp. 242-245, Jun. 2017. https://doi. org/10.1109/LAWP.2016.2570859 
[11] K. Luk, C. Mak, Y. Chow \& K. Lee, "Broadband microstrip patch antenna," Electron. Lett., vol. 34, no. 15, p. 1442-1443, Jul. 1998. https://doi.org/10.1049/el:19981009

[12] K. Luk, C. Mak, Y. Chow \& K. Lee, "Experimental study of a microstrip patch antenna with an Lshaped probe," IEEE Trans. Antennas Propag., vol. 48, no. 5, pp. 777-783, May. 2000. https://doi. org/10.1109/8.855497

[13] S.-L. Yang \& K. Luk, "Design of a Wide-Band L-Probe Patch Antenna for Pattern Reconfiguration or Diversity Applications," IEEE Trans. Antennas Propag., vol. 54, no. 2, pp. 433-438, Feb. 2006. https:// doi.org/10.1109/TAP.2005.863376

[14] S.-L. Yang \& K. Luk, "A Wideband L-Probes Fed Circularly-Polarized Reconfigurable Microstrip Patch Antenna," IEEE Trans. Antennas Propag., vol. 56, no. 2, pp. 581-584, Feb. 2008. https://doi.org/10.1109/ TAP.2007.915486

[15] B. Cao, H. Wang, Y. Huang \& J. Zheng, "High-Gain L-Probe Excited Substrate Integrated Cavity Antenna Array with LTCC-Based Gap Waveguide Feeding Network for W-Band Application," IEEE Trans. Antennas Propag., vol. 63, no. 12, pp. 5465-5474, Dec. 2015. https://doi.org/10.1109/TAP.2015.2481483

[16] H. W. Lai \& K. Luk, "An L-probe fed patch antenna loaded with multiple dielectric layers," in 4th AsiaPacific Conference on Antennas and Propagation, APCAP, Bali Island, IDN, 2015, pp. 263-264. https:// doi.org/10.1109/APCAP.2015.7374365

[17] Y. Yoshitake \& T. Fujimoto, "Stacked microstrip antenna fed by an L-probe for quadruple band operation," IET Microwaves, Antennas Propag., vol. 9, no. 4, pp. 360-368, Mar. 2015. https://doi.org/10.1049/ iet-map.2014.0362

[18] L. Li, Y. Huang, L. Zhou \& F. Wang, "Triple-Band Antenna With Shorted Annular Ring for High-Precision GNSS Applications," IEEE Antennas Wirel. Propag. Lett., vol. 15, pp. 942-945, Sep. 2015. https:// doi.org/10.1109/LAWP.2015.2482604

[19] I. T. McMichael, "A Mechanically Reconfigurable Patch Antenna With Polarization Diversity," IEEE Antennas Wirel. Propag. Lett., vol. 17, no. 7, pp. 1186-1189, Jul. 2018. https://doi.org/10.1109/ LAWP.2018.2837902

[20] D. Pozar, Microwave Engineering. Hoboken, USA: Wiley, 2012.

Carlos Arturo Suarez Fajardo received the MSc. and PhD. degrees in Telecommunications from the Universidad Politècnica de Valencia, Valencia, Spain, in 2003 and 2006, respectively, for which he joined the electromagnetic radiation group (GRE) of the Universidad Politécnica de Valencia, Spain. Currently holds the position of titular Professor at the Universidad Distrital Francisco José de Caldas (Bogotá, Colombia). Up to date, he has published more than 50 papers in international journals and conferences in the field of antennas. He is a reviewer of the Chilean Journal Engineering, Journal of Antennas and Propagation (IJAP), and DYNA Journal. His research interests include wideband and multi-band planar antennas, microwave engineering, Metamaterial applications and small satellite communication systems. https:// orcid.org/0000-0002-1460-5831

Jeison Jair Ariza Pulido is Electronic engineer from the Universidad Distrital Francisco José de Caldas (Bogotá, Colombia). In 2015, he joined the Group of Electromagnetic Radiation and Optical Communications (GRECO) as a researcher at the undergraduate level. His research interests include design and optimization of microstrip antennas of small size. https:// orcid.org/0000-0002-2214-0966

Sergio Esteban Mejía Serrano is Electronic engineer from the Universidad Distrital Francisco José de Caldas (Bogotá, Colombia). In 2015, he joined the Group of Electromagnetic Radiation and Optical Communications (GRECO) as a researcher at the undergraduate level. His research interests include design and optimization of microstrip antennas of small size. https://orcid.org/0000-0002-8671-1844

Gustavo Adolfo Puerto Leguizamón is Telecommunications engineer. In 2003, he joined the Group of Optical and Quantum Communications of the Universidad Politécnica de Valencia, Spain. Ph.D. in Telecommunications in 2008 and postdoctoral researcher at the Institute of Telecommunications and Multimedia Applications at the same university until 2011. Since 2012, he is Assistant Professor at the Universidad Distrital Francisco José de Caldas (Bogotá, Colombia). Up to date, he has published more than 50 articles in international journals and conferences in the field of optical networks. He is evaluator of Colciencias and of the journals IEEE Journal on Lightwave Technologies, IEEE Photonic Technology Letters and Optics Express. His research interests include radio over fiber systems, optical networking and optical access networks. https://orcid.org/0000-0002-6420-9693 